\title{
CONTRIBUIÇÃO DO GOALBALL PARA A ORIENTAÇÃO E MOBILIDADE SOB A PERCEPÇÃO DOS ATLETAS DE GOALBALL
}

\author{
Roger Lima Scherer \\ Universidade Federal de Santa Catarina, Florianópolis, Santa Catarina, Brasil
}

\section{Luiz Alberto Rodrigues}

Associação Catarinense de Esportes Adaptados, Florianópolis, Santa Catarina, Brasil

\section{Luciano Lazzaris Fernandes}

Universidade Federal de Santa Catarina, Florianópolis, Santa Catarina, Brasil

\section{Resumo}

O presente estudo é caracterizado como descritivo-exploratório e teve como objetivo geral verificar a relação entre a prática do goalball e a orientação e mobilidade das pessoas com deficiência visual. Foram aplicados 79 questionários com os atletas de goalball participantes da Copa Brasil de Goalball, no ano de 2007. A contribuição do goalball na orientação e mobilidade, sob a perspectiva dos atletas, foi positiva, sendo de suma importância para o desenvolvimento motor e também para a reabilitação da pessoa com deficiência visual, pois desenvolve percepções sensório-motoras como audição e tato, além de aguçar a noção espacial e aumentar os níveis de concentração.

Palavras-chave: Deficiência Visual - Orientação e Mobilidade - Goalball (Re)habilitação

\section{Introdução}

deficiência visual é uma limitação sensorial que poder compro-
meter o desenvolvimento motor, afetivo, social e cognitivo de uma pessoa (BUENO; RESA, 1995). Esta falta de visão pode dificultar a compreensão e interiorização do esquema corporal, pela dificuldade de assumir modelos de referência e de estimulação motora (MOSQUERA 2000). A dificuldade em criar uma imagem corporal varia de acordo com o seu grau de deficiência e sua história de vida. Além disso, pode acarretar alguns problemas para atividades simples em sua vida diária, assim como em sua orientação e mobilidade. Para o deslocamento com segurança e eficiência, conhecimentos da posição, da relação ao espaço e o conhecimento corporal são fundamentais 
(MASI, 2003). Entretanto, para amenizar estes comprometimentos, a estimulação torna-se importante. Habilidades e capacidades, tais como mobilidade, imagem corporal, lateralidade, coordenação motora entre outras (CONDE, 1994), necessitam ser estimuladas precocemente para trazer benefícios para esta população. Com isso, procura-se auxiliar a independência do indivíduo e sua qualidade de vida.

A prática de atividade física é uma das formas de estimulação para a pessoa com deficiência visual. Elas devem praticar atividades diárias que permitam o desenvolvimento de habilidades motoras básicas para desenvolvimento da motricidade geral e desenvolvimento motor (GAVIDIA E PRADO, 2005). Ainda, as atividades devem dar ênfase a orientação espacial e equilíbrio, proporcionando melhor interação social (CIDADE; FREITAS, 2002). Uma das possibilidades de atividade física são os esportes adaptados (praticado pelas pessoas com deficiência) que estão cada vez mais conhecidos, principalmente após os resultados das delegações brasileiras nos Para-Pans e Paraolimpíadas. Çolak et al. (2004) destacam que o esporte é um fator de integração, além de proporcionar um desenvolvimento das capacidades físicas, oportunizando uma melhora do controle corporal, podendo inclusive ser um método de reabilitação.

Dentre os esportes adaptados às pessoas com deficiência visual encontra-se o goalball. Atualmente este esporte faz parte de um elenco de modalidades disputadas nas Paraolimpíadas. Sua origem veio logo após a Segunda Guerra Mundial para auxiliar na reabilitação dos veteranos da guerra. São três jogadores titulares por equipe, podendo até três reservas. $\mathrm{O}$ jogo não possui contato físico entre as equipes. Dentro de uma quadra de 18 metros de comprimento por nove de largura, os atletas devem defender sua trave que mede nove metros de largura e $1 \mathrm{~m} 30 \mathrm{~cm}$ de altura. O objetivo do jogo é fazer gols através de arremessos com as mãos e defender utilizando a extensão de seu corpo. Este jogo apresenta uma diferença para os demais desportos para pessoas com deficiência visual que é a possibilidade de jogarem juntos atletas de várias classificações esportivas, sendo, cegos (B1) e atletas com baixa visão (B2 e B3) (NASCIMENTO; MORATO, 2006).

$\mathrm{O}$ goalball, que inicialmente foi proposto como terapia às pessoas com deficiência visual e que alcançou um cenário competitivo mundial, apresenta indícios de auxílio na orientação e mobilidade das pessoas com deficiência visual praticantes desta modalidade. Desta forma, o objetivo do presente estudo foi analisar, na perspectiva dos atletas, se 
existe contribuição do goalball para a orientação e mobilidade das pessoas com deficiência visual.

\section{Método}

A presente pesquisa tem uma característica descritivo-exploratória, pois segundo Köche (2006, p.126), a pesquisa exploratória tem como objetivo fundamental "o de descrever ou caracterizar a natureza das variáveis que se quer conhecer". O autor ainda menciona que na pesquisa exploratória "não se trabalha com a relação entre variáveis, mas com o levantamento da presença das variáveis e da sua caracterização quantitativa ou qualitativa".

Além disso, a pesquisa é considerada descritiva, pois "as pesquisas descritivas têm como objetivo primordial a descrição das características de determinada população ou fenômeno ou, então, o estabelecimento de relações entre variáveis"[...] "têm por objetivo estudar as características de um grupo"[...] "levantar as opiniões, atitudes e crenças de uma população" (GIL, 1991, p.46).O estudo foi conduzido respeitando todos os preceitos éticos de pesquisa com Seres Humanos da resolução 196/96.

\section{Amostra}

Participaram do estudo todos os atletas envolvidos no evento, ou seja, 42 atletas homens e 37 mulheres participantes da Copa Brasil de Goalball serie A 2007, realizada em Ribeirão Preto/SP. Havia um ranking pré-estabelecido, participando apenas as equipes melhores classificadas no Brasil em 2007. Apesar de haver 12 vagas no naipe masculino, apenas oito equipes estavam presentes, sendo três da região sul, quatro da região sudeste e uma da região nordeste. No naipe feminino foram oito vagas com sete equipes participantes, sendo duas da região sul, uma da região nordeste e quatro da região sudeste.

A faixa etária dos participantes foi entre 18 e 58 anos (média de idade de $31,39 \pm 9,9$ ).

Dos 79 atletas, $46 \%$ adquiriram seu problema de visão até os três anos de idade, o que pode ser considerado congênito, tendo em sua grande maioria (67\%) adquirido seu problema visual antes dos 10 anos de idade. Dentre os atletas, apenas um teve acompanhamento especializado de estimulação nesta fase da vida. 
Neste evento o número de atletas com classe esportiva B1 foi muito superior aos demais, sendo $56 \%$ atletas cegos e $44 \%$ atletas com baixa visão, sendo (B2 - 31\% e B3 - 13\%).

\section{Instrumento}

O instrumento para coleta de dados (Quadro 1) foi um roteiro de entrevista semi estruturado criado para a pesquisa, que passou por um processo de validação de conteúdo, através de professores do Centro de Desporto da Universidade Federal de Santa Catarina no ano de 2007. O mesmo possui 28 itens, abordando questões pessoais para descrição da população, além de questões relacionadas à prática de atividade física, treinamento de goalball, locomoção diária e orientação e mobilidade. 


\begin{tabular}{|c|}
\hline ROTEIRO DE ENTREVISTA SEMI ESTRUTURADO \\
\hline 1. Qual a sua idade? \\
\hline 2. Sexo? (M) \\
\hline 3. Classificação esportiva? - B1 - B2 \\
\hline 4. Quando você obteve o problema de visão (anos)? \\
\hline $\begin{array}{llll}\text { 5. O que causou este problema? - Retinose Pigmentar } & \text { - Glaucoma } & \text { - Diabetes } \\
\text { - Deslocamento de retina } & \text { - Taxoplasmose } & \text { - Rubéola } & \text { - Catarata } \\
\text { - Degeneração Macular Senil } & \text { - Traumatismos } & \text { - Outros } & \\
\end{array}$ \\
\hline 6. Você estudou em escola regular? - Sim \\
\hline $\begin{array}{l}\text { 7. Nesse período você participava ativamente das aulas de Educação Física? } \\
\text { - Sim }\end{array}$ \\
\hline 8. Seu professor desenvolveu algum trabalho de orientação e mobilidade em suas aulas? \\
\hline $\begin{array}{l}\text { 9. Quais atividades fazia quando era mais novo? } \\
\begin{array}{llll}\text { - Jogar bola - Nadar } & \text { - Correr } \quad \text { - Brincar com amigos } \\
\text { - Andar de bicicleta } & \text { - Brincadeiras de montar - outras }\end{array}\end{array}$ \\
\hline $\begin{array}{l}\text { 10. Passou por algum trabalho de estimulação precoce? } \\
\begin{array}{lll}\text { - Sim } & \text { - Não } & \text { (S) Quando e qual? }\end{array}\end{array}$ \\
\hline $\begin{array}{l}\text { 11. A quantos anos pratica o goalball? } \\
-1 \text { ano }-2 \text { anos }-3 \text { anos }-4 \text { anos }-5 \text { anos ou mais }\end{array}$ \\
\hline $\begin{array}{l}\text { 12. Quantas vezes pratica por semana? } \\
-1 \mathrm{vez}-2 \text { vezes } \quad-3 \text { vezes }\end{array}$ \\
\hline $\begin{array}{l}\text { 13. Quantas horas por treino? } \\
-1 \text { hora }-2 \text { horas } \quad-3 \text { horas }-4 \text { horas } \quad \text { - outras }\end{array}$ \\
\hline $\begin{array}{l}\text { 14. Faz algum trabalho de orientação na quadra? } \\
\text { - Sim } \quad \text { - Não }\end{array}$ \\
\hline $\begin{array}{l}\text { 15. Qual tipo de orientação ? } \\
\text {-Tátil r - Auditiva }\end{array}$ \\
\hline $\begin{array}{l}\text { 16. Participou de algum curso de orientação e mobilidade? } \\
\text { - Sim }\end{array}$ \\
\hline 17. Quando? (Data) \\
\hline $\begin{array}{l}\text { 18. Caminha com autonomia e independência? } \\
- \text { Sim } \quad \text { - Nãor } \quad \text { - As vezes }\end{array}$ \\
\hline $\begin{array}{l}\text { 20. Fez ou faz atividades físicas ou esportivas juntamente com o curso de orientação e } \\
\text { mobilidade. } \\
\text { - Sim - Não }\end{array}$ \\
\hline $\begin{array}{l}\text { 21. Quais? } \\
\text { - Jogos diversos - Caminhadas - Correr - Nadar - Goalball }\end{array}$ \\
\hline $\begin{array}{l}\text { 22. O curso de orientação e mobilidade auxiliou na prática do goalball? } \\
\begin{array}{lll}-\operatorname{Sim} & \text { - Não } & \text { (S) De que forma? }\end{array}\end{array}$ \\
\hline $\begin{array}{l}\text { 23. O goalball auxiliou em sua orientação e mobilidade? } \\
\begin{array}{lll}\text { - Sim } & \text { - Não } & \text { (S) De que forma? }\end{array}\end{array}$ \\
\hline $\begin{array}{l}\text { 24. Na sua opinião qual o tipo de informação é necessário em um jogo de goalball? } \\
\begin{array}{llll}\text { - Auditivas } & \text { - Táteis - Espacial } & \text { - Cinestésica } & \text { - Outras }\end{array}\end{array}$ \\
\hline $\begin{array}{l}\text { 25. Qual o tipo de informação é necessário para você se deslocar com autonomia pela rua? } \\
\begin{array}{llll}\text { - Auditivas } & - \text { Táteis - Espacial } & \text { - Cinestésica } & \text { - Outras }\end{array}\end{array}$ \\
\hline $\begin{array}{l}\text { 26. Sente diferença antes de praticar goalball e após para sua locomoção diária? } \\
\begin{array}{llll}- \text { Sim } & - \text { Não } & - \text { As vezes } & \text { (S) Qual? }\end{array}\end{array}$ \\
\hline $\begin{array}{l}\text { 27. Você acha válido a prática de goalball paralelo ao trabalho de orientação e mobilidade na } \\
\text { reabilitação do cego ou baixa visão? } \\
\begin{array}{lll}\text { - Sim } & \text { - Não } & \text { (S) Porque? }\end{array}\end{array}$ \\
\hline 28. Comentário e observações: \\
\hline
\end{tabular}

Quadro 1: Roteiro de entrevista aplicado na Copa Brasil de Goalball 


\section{Análise de dados}

Os dados foram tabulados no software SPSS, versão 16.0 for Windows. E para análise dos dados foi utilizado apenas à estatística descritiva (frequências, percentagens, medidas de tendência central e de dispersão).

\section{Resultados}

São inúmeras as causas precursoras para a deficiência visual. Entre os participantes o glaucoma $n=15$, retinose pigmentar $n=10$, deslocamento de retina $n=7$ e traumatismos $n=6$, foram as mais incidentes, além de toxoplasmose $n=4$ e catarata $n=3$, outras foram citadas apenas uma vez cada, tais como: galactose na infância, drusas de papila, retinoplastoma, panidel do nervo, entre outras.

$\mathrm{Na}$ Tabela 1, os atletas informaram várias atividades que praticavam durante sua infância e pré-adolescência.

\begin{tabular}{lcccc}
\hline \multicolumn{2}{l}{ Tabela 1 - Atividades praticadas durante a infância e pré-adolescência. } & \multicolumn{2}{c}{ MULHERES } \\
\hline Atividade fisica & HOMENS & $\%$ & $\mathrm{n}$ & $\%$ \\
Brincar com amigos & $\mathrm{n}$ & 83,3 & 24 & 64,8 \\
Andar de bicicleta & 35 & 76,2 & 18 & 48,6 \\
Jogar bola & 32 & 71,4 & 13 & 35,1 \\
Brincadeiras de correr & 30 & 69,0 & 22 & 59,4 \\
Nadar & 29 & 35,7 & 8 & 21,6 \\
Outras** & 15 & 19,0 & 12 & 32,4 \\
Brincar de montar* & 8 & 16,7 & 7 & 18,9 \\
Artes Marciais & 7 & 7,1 & 0 & 0,0 \\
Nada & 3 & 2,4 & 4 & 10,8 \\
Balé & 1 & 0,0 & 2 & 5,4 \\
Dança & 0 & 0,0 & 3 & 8,1 \\
Ginástica Olímpica & 0 & 0,0 & 2 & 5,4 \\
Vôlei & 0 & 2 & 5,4 \\
\hline
\end{tabular}

* - brincar com jogos de montar como quebra cabeça ou bloquinhos;

** - outras atividades diversas elencadas uma única vez

Entre os atletas, apenas 39 (49,4\%) mencionaram participar de aulas de orientação e mobilidade, apesar destes dados, $86,1 \%$ deles responderam que possuem autonomia em sua locomoção diária e os outros $13,9 \%$ falaram que às vezes possuem autonomia.

$\mathrm{Na}$ Tabela 2, estão descritas as características dos jogadores de acordo com o tempo de prática, frequência semanal e horas de treinamento por sessão. 
Tabela 2 - Características do treinamento de goalball com relação a tempo de prática, frequência semanal e horas de treinamento dos participantes da Copa Brasil de Goalball serie A - 2007

\begin{tabular}{lcc}
\hline Anos de prática & $\mathbf{N}$ & $\mathbf{\%}$ \\
\hline 1 ano & 4 & $\mathbf{5 , 1 0}$ \\
2 anos & 6 & $\mathbf{7 , 6 0}$ \\
3 anos & 9 & $\mathbf{1 1 , 4 0}$ \\
4 anos & 5 & $\mathbf{6 , 3 0}$ \\
Acima de 5 anos & 55 & $\mathbf{6 9 , 6 0}$ \\
\hline Frequência semanal & $\mathbf{N}$ & $\mathbf{\%}$ \\
\hline 1 vez & 10 & $\mathbf{1 2 , 6 5}$ \\
2 vezes & 13 & $\mathbf{1 6 , 4 5}$ \\
3 vezes & 43 & $\mathbf{5 4 , 4 0}$ \\
4 vezes & 4 & $\mathbf{5 , 1 0}$ \\
5 vezes & 8 & $\mathbf{1 0 , 1 0}$ \\
Não treina no momento & 1 & $\mathbf{1 , 3 0}$ \\
\hline Sessão dos treinamentos & $\mathbf{N}$ & $\mathbf{9}$ \\
\hline 1 hora & 4 & $\mathbf{5 , 1 0}$ \\
2 horas & 33 & $\mathbf{4 1 , 8 0}$ \\
2 a 3 horas & 11 & $\mathbf{1 3 , 9 0}$ \\
3 horas & 23 & $\mathbf{2 9 , 1 0}$ \\
3 a 4 horas & 5 & $\mathbf{6 , 3 0}$ \\
4 horas & 3 & $\mathbf{3 , 8 0}$ \\
\hline
\end{tabular}

Dos 79 atletas, apenas um não realizou atividades de orientação e mobilidade durante os treinamentos de goalball. Dentre aqueles que fizeram estas atividades, $86 \%$ mencionaram ser de orientação tátil e auditiva, principalmente. Entre os participantes, 47 responderam que o goalball auxiliou em sua locomoção diária. Outros 25 responderam não terem feito aulas de orientação e mobilidade para responder com precisão e sete relataram não praticarem goalball na época que fizeram o curso.

Os aspectos que mais contribuíram no dia a dia dos praticantes de goalball foram: uma melhor orientação (geral, espacial, noções de distância e espaço), concentração, e aguçou ainda mais sua percepção (geral, auditiva e tátil), sendo a percepção auditiva mais mencionada.

Na tabela 3 são apresentadas as percepções elencadas no goalball e para se locomover no dia a dia.

Tabela 3 - Percepções elencadas para a prática do goalball e para locomoção diária

\begin{tabular}{lcccc}
\hline & \multicolumn{3}{c}{ Goalball } & \multicolumn{3}{c}{ Locomoção diária } \\
\hline Percepção & $\mathbf{n}$ & $\%$ & $\mathbf{n}$ & $\%$ \\
Auditiva & 79 & 100 & 71 & 89,9 \\
Tátil & 69 & 87,3 & 44 & 55,7 \\
Espacial & 61 & 77,2 & 50 & 63,3 \\
Cinestésica & 51 & 64,5 & 29 & 36,7 \\
Olfativa & 0 & 0 & 1 & 1,3 \\
Visual & 0 & 0 & 10 & 12,6 \\
\hline
\end{tabular}


Com relação às mudanças após a prática do goalball, 72\% dos participantes afirmaram que sentiram diferenças. Entre os homens, as principais mudanças foram à percepção, principalmente a auditiva, além da autoconfiança e a locomoção de forma geral em sua autonomia. Já entre as mulheres evidenciou-se uma melhora na segurança, noção espacial, na locomoção de modo geral e na agilidade.

Entre os atletas, 94\% mencionaram que é válido o trabalho paralelo, mencionando sua contribuição para audição, aguçando e ensinando a diferenciar melhor os sons, além de auxiliar em sua confiança, melhora da autoestima, desenvolvimento da percepção tátil, melhora da orientação, noção espacial e agilidade. Alguns relataram sentirem-se mais úteis, possuir mais segurança e coragem, além de desenvolverem mais independência e autonomia e melhorar o condicionamento físico.

\section{Discussão}

A orientação e a mobilidade, na concepção de Russo, Junior e Santos (2001), são técnicas através de treinamentos sensório-perceptivos que a pessoa com deficiência visual busca desenvolver uma locomoção mais desembaraçada tornando sua orientação mais segura. Porém essas habilidades são realizadas de forma sistematizada, muitas vezes fugindo da realidade diária das ruas. Os autores ainda argumentam que essas técnicas ficam circunscritas ao aspecto de reproduzir posturas ou movimentos indicativos, impossibilitando o indivíduo de interagir, direta ou indiretamente, com o seu meio. Desta forma o aluno necessita de um conjunto de ações ou métodos que ajudem a construir um novo posicionamento sobre a sua realidade.

A perda da mobilidade independente poderá ser considerada o maior obstáculo ao indivíduo pela sua deficiência na visão, fato que parece alterar substancial e significativamente o seu próprio estilo de vida (HOFFMANN, s.d). Souza (2007) enfatiza que há necessidade de evitar a mecanização das expressões do corpo, proporcionando aos alunos mobilidade e possibilidades de diversas vivências corporais para um bom convívio em sociedade. É importante que a pessoa com deficiência visual sinta seu corpo no espaço usando a locomoção e a orientação, passando a adquirir consciência da existência de objetos e de seu próprio corpo.

Além de auxiliar no desenvolvimento motor, Castro (1996/2) en- 
tende que no processo que envolve a aprendizagem das técnicas de orientação e mobilidade para as pessoas com deficiência visual, há a necessidade de adquirir uma boa aptidão física, evitando a excessiva inatividade física que é comum entre esta população.

Muitos atletas mencionaram brincar com outras crianças durante sua infância, auxiliando em seu desenvolvimento afetivo-social, além do desenvolvimento psicomotor diante das atividades apresentadas. Segundo Oliveira Filho (2003), Diehl (2006), Monteiro (2004), Padula e Spungin (1996) e Figueira (s. d.), é de suma importância estimular vivências nos primeiros anos de vida com a intenção de prevenir outras alterações além da cegueira. Estas práticas na infância podem ter auxiliado diretamente o desenvolvimento motor, cognitivo, afetivo e social destes atletas que foram ativos na infância para uma orientação e mobilidade mais independente na fase adulta.

Como a grande maioria dos atletas adquiriu seu problema de visão antes ou durante o período de idade escolar, os professores de Educação Física poderiam iniciar em suas atividades algumas orientações para desenvolvimento da orientação e mobilidade destes alunos com problema de visão.

Conforme Winnick (2004), o esporte sendo adaptado ou não, poderá ser usado como uma parte dos programas de terapia recreativa, corretiva, esportiva ou de bem-estar. Um dos esportes que pode contribuir com esta falta de vivência motora é o goalball, desporto praticado pelas pessoas com deficiência visual.

Mais de $90 \%$ dos atletas de goalball treinam duas horas ou mais, podendo a sessão de treinamento ter duração de até quatro horas e, esses treinamentos são realizados pelo menos três vezes por semana para a maioria (54\%). Quase $70 \%$ dos atletas participantes desta pesquisa estão na modalidade a mais de cinco anos.

Um complemento para auxiliar na independência durante a locomoção pode ser advindo do trabalho de orientação que é feito em quadra pelos técnicos de goalball. A freqüência semanal assim como o tempo despendido para a prática de atividade física ao qual a pessoa pratica esta intimamente ligada ao desenvolvimento de habilidades motoras, desempenhando um papel fundamental na sua efetividade (WEINECK, 1999). Nogueira, Shibata e Gagliardi (2009) encontraram em seu estudo que a especificidade da modalidade, interfere diretamente no equilíbrio dinâmico dos seus praticantes com deficiência visual total e congênita, fato este, justificado principalmente pela soli- 
citação dos sistemas vestibular e somatossensitivo.

Diariamente a pessoa esta recebendo constantes informações do meio externo, sendo estas captadas pelos órgãos do sentido. Os atletas relataram (10 dos 79) que nas ruas há uma informação que não pode ser utilizada no jogo de goalball que são as informações recebidas da visão. Isso acontece com as pessoas com baixa visão que normalmente buscam utilizar seu resíduo visual em suas atividades diárias.

A audição, o tato e a orientação espacial são as percepções mais evidenciadas pelos atletas tanto na rua como durante o goalball. A percepção cinestésica foi citada com expressividade apenas durante os jogos de goalball. Segundo Caldeira (2005), o goalball é um esporte coletivo e essencialmente baseado nas percepções auditivas e táteis, assim como na orientação espacial.

Silva (2008) destaca que a orientação espacial durante o jogo é necessário para o jogador saber sua exata posição em quadra, sendo que esta capacidade, também será muito útil na vida diária. A pessoa com deficiência visual com uma orientação espacial bem apurada terá maior facilidade para discriminar e se orientar no caminho a ser percorrido com maior independência e segurança.

Diante da semelhança entre os trabalhos apresentados pelo goalball e pela orientação e mobilidade, e os caminhos para buscarem objetivos semelhantes, porém com finalidades diversas, ambos trabalham sensações como audição, tato e noção espacial. Estes fatores implicam diretamente em sua locomoção e, consequentemente, em seu estilo de vida.

\section{Conclusão}

A prática do goalball demonstrou, através da percepção dos atletas, trazer benefícios as pessoas com deficiência visual de uma forma geral, proporcionando desenvolvimento em aspectos como mobilidade, lateralidade, coordenação, marcha, equilíbrio, agilidade e noção espacial. Além da parte psicomotora, o goalball poderá contribuir na melhoria da concentração e independência, além de dar forças para enfrentar o medo e quebrar barreiras. Essa prática oportuniza o convívio com outras pessoas com deficiência visual, sendo esta interação decorrente do esporte essencial para o desenvolvimento sócio-afetivo.

Os atletas também relataram uma melhora na percepção sensóriomotora, aguçando principalmente a audição e o tato. A semelhança en- 
tre as percepções utilizadas no dia a dia das pessoas com deficiência visual, assim como durante um jogo ou treinamento de goalball são pontos positivos no desenvolvimento da orientação e mobilidade destas pessoas.

A semelhança entre algumas percepções, habilidades e capacidades motoras, além do auxilio nos aspectos afetivo e psicossocial poderão acelerar o processo de (re) habilitação destas pessoas, tornando-as mais independentes em sua orientação e locomoção diária. O desenvolvimento do goalball para a (re) habilitação deve auxiliar a orientação e mobilidade a partir do desenvolvimento sensório-motor, além de melhorar o equilíbrio, concentração, coordenação, entre outros.

Desta forma a prática deste esporte juntamente com as técnicas de orientação e mobilidade sob a perspectiva dos atletas poderá auxiliar de forma incisiva em uma locomoção mais segura e independente para as pessoas com deficiência visual.

Goalball contribution for orientation and mobility in the perception of goalball athletes

\begin{abstract}
The present study is characterized as descriptive-exploratory and have the objective to investigate the relationship between the practice of goalball and orientation and mobility for people with visual impairments. 79 questionnaires were administered to goalball athletes participants of Goalball Brazil Cup, in 2007. The contribution of goalball orientation and mobility from the perspective of the athletes was positive, which is extremely important for motor development and also for the rehabilitation of the person with visual impairments, because it develops motor sensory perceptions such as hearing and touching, as well as improves the concept space and increase levels of concentration.
\end{abstract}

Keywords: Visual Impairment - Orientation and Mobility - Goalball - (Re) Habilitation

Contribución del goalball para la orientación y movilidad em la percepción de los atletas de goalball

\title{
Resumen
}

El presente estudio se caracteriza por ser descriptiva y exploratoria y tuvo como objetivo investigar la relación entre la práctica de goalball y orientación y movilidad para personas con impedimentos visuales. 79 cuestionarios fueron administrados a los atletas participantes de goalball de la Copa Brasil, en 2007. La contribución de la orientación y la movilidad de goalball desde la perspectiva de los atletas fue positiva, que es extremadamente importante para el desarrollo motor y también para la rehabilitación de las personas con discapacidad visual, ya que 
desarrolla las percepciones sensoriales como el motor de oído y el tacto, así como afinar el concepto de espacio e incrementar los niveles de concentración.

Palabras clave: Deficiencia Vvisual - Orientación y Movilidad - Goalball - (Re) Habilitacióne

\section{Referências}

ABNT. NBR 9050:2004. Acessibilidade a edificações, mobiliário, espaços e equipamentos urbanos. $2^{\circ}$ ed. Rio de Janeiro: ABNT, 2004, $97 \mathrm{p}$.

BITTENCOUT, L. S. et al. Acessibilidade e cidadania: Barreiras arquitetônicas e exclusão social dos portadores de deficiência física. In: Anais do $2^{\circ}$ Congresso de Extensão Universitária. Belo Horizonte, 2004.

BUENO, S. T.; RESA, J. A. Z. Educación Física para niños y niñas com necessidades educativas especiales. Málaga: Aljibe, 1995.

CALDEIRA, Natalia. Análise Quantitativa do Goalball. Campinas, 2005. 59 folhas. TCC (Monografia) Faculdade de Educação Física. Universidade Estadual de Campinas.

CASTRO, J. A. M. Educação Física, orientação e mobilidade de deficiência visual. Revista Movimento. Porto Alegre, 1996/2, Ano III, n. 5 , p. $8-12$

CIDADE, R. E. A. e FREITAS, P. S. Introdução à Educação Física e ao Desporto para pessoas portadoras de deficiência. Curitiba: UFPR, 2002.

ÇOLAK, T. et al. Physical fitness levels of blind and visually impaired goalball team players. Isokinetics and Exercise Science, v. 12, p. 247252, 2004.

DIEHL, R. M. Jogando com as diferenças. São Paulo: Phorte, 2006.

FIGUEIRA, M. M. A. Assistência fisioterápica à criança portadora de cegueira congênita. Disponível em: $<\mathrm{http}$ :/www.deficientesvisuais.org.br/Artigo 16.htm> Acesso em: 15 de janeiro de 2009.

GAVIDIA, A. e PRADO, J. R. Diagnóstico sobre el desarrollo de las 
habilidades motrices básicas en ciegos y deficientes visuales. Revista Digital - Buenos Aires - Año 10 - No 88 - Setiembre de 2005. Disponível em: <http://www.efdeportes.com/efd88/visuales.htm> Acesso em: 30 de março de 2009.

GIL, A. C. Como elaborar projetos de pesquisa. $3^{\circ}$ ed. São Paulo: Atlas, 1991.

HOFFMANN, S. B. Benefícios da Orientação e Mobilidade - estudo intercultural entre Brasil e Portugal. Disponível em: $<\mathrm{http}$ ://www.diversidadeemcena.net/artigo02.htm $>$ Acesso em: $15 \mathrm{de}$ janeiro de 2009.

KÖCHE, J. C. Fundamentos de metodologia científica: Teoria da ciência e iniciação à pesquisa $23^{\circ}$ ed. Petrópolis - RJ: Editora Vozes, 2006.

MASI, I. Conceitos - Aquisição básica para a orientação e mobilidade. In: MACHADO, E. V. et al Orientação e Mobilidade: Conhecimentos básicos para a inclusão da pessoa com deficiência visual. Brasília, MEC - SEESP, 2003, p. 37-55.

MONTEIRO, L. M. F. da S. A importância das atividades corporais no processo de alfabetização da criança cega. Benjamin Constant: publicação técnico-científica do Centro de Pesquisa, Documentação e Informação do Instituto Benjamin Constant/Mec - Ibcentro, Rio de Janeiro, dezembro 2004, n.29.

MOSQUERA, C. Educação física para deficientes visuais. Rio de Janeiro: Sprint, 2000.

NOGUEIRA, C. R.; SHIBATA, J.; GAGLIARDI, J. F. L. Comparação do Equilíbrio estático e dinâmico entre atletas com deficiência visual, praticantes de goalball e atletismo. Revista Brasileira de Ciência e Movimento, v. 17, n. 2, p. 1-17, 2009.

OLIVEIRA FILHO, C. W. Atividade Físico-esportiva para Pessoas Cegas e com Baixa Visão. In: DUARTE, E. LIMA, S. M. T. Atividade Física para Pessoas com Necessidades Especiais: Experiências e Intervenções Pedagógicas. Rio de Janeiro: Guanabara, 2003, p.23-32.

PADULA, W. V. e SPUNGIN, S. J. A criança visualmente incapacitada, do nascimento até a idade pré-escolar: A importância da estimula- 
ção visual. Benjamin Constant: publicação técnico-científica do Centro de Pesquisa, Documentação e Informação do Instituto Benjamin Constant/Mec - Ibcentro, Rio de Janeiro, maio 1996, n.3, p.08-11.

RUSSO JUNIOR, W. e SANTOS, L. J. M. O judô como atividade pedagógica desportiva complementar, em um processo de orientação e mobilidade para portadores de deficiência visual. Revista Digital Buenos Aires - Año 7 - $\mathrm{N}^{\circ} 35$ - Abril de 2001. Disponível em: $<$ http://www.efdeportes.com/efd35/judo.htm> Acesso em: 05 de abril de 2009.

SILVA, G. C. P. Tempo de reação e a eficiência do jogador de goalball na intercepção /defesa do lançamento/ataque. 2008. 80f. Dissertação (Mestrado em Educação Física) - Programa de Pós Graduação UEM/UEL, Maringa, 2008.

SOBRINHO, A. S. O esporte adaptado e paraolímpico como direito da criança e do adolescente. In: CONDE, A. J. M. Manual de Orientação para os professores de Educação Física: Introdução, Brasília: Comitê Paraolímpico Brasileiro, 2006, p.24-48.

SOONG, G. P. et al. Does Mobility Performance of Visually Impaired Adults Improve Immediately After Orientation and Mobility Training? Optometry and Vision Science, v. 78, n.9, p. 657-666, 2001.

SOUZA, M. P. Educação Física adaptada para pessoas portadoras de necessidades visuais especiais. Revista Digital - Buenos Aires Año 12 - $\mathrm{N}^{\circ} 111$ - Agosto de 2007. Disponível em: <http://www.efdeportes.com/efd111/educacao-fisica-adaptada.htm $>$ Acesso em: 16 de janeiro de 2009.

WEINECK, J. Treinamento Ideal: Instruções técnicas sobre o desempenho fisiológico, incluindo considerações específicas de treinamento infantil e juvenil. $9^{\circ}$ Ed. São Paulo, Manole, 1999.

WINNICK, J. P. Educação Física e esportes adaptados. $3^{\circ}$ ed. Trad. Fernando Augusto Lopes. Barueri: Ed. Manole, 2004.

Recebido em: 06/08/2010

Revisado em: 31/07/2011

Aprovado em: 20/09/2011

Pensar a Prática, Goiânia, v. 14, n. 3, p. 1-15, set./dez. 2011 


\section{Endereço para correspondência}

rogerlscherer@gmail.com

Roger Lima Scherer

Universidade Federal de Santa Catarina

Centro de Desportos, Departamento de Educação Física

Campus Universitário

Trindade

88040900 - Florianopolis, SC - Brasil 